\title{
A flexigurança em Portugal: Desafios e dilemas da sua aplicação
}

Flexicurity in Portugal: The challenges and dilemmas of implementation

La flexicurité au Portugal: défis et dilemmes de son application

\section{Hermes Augusto Costa}

\section{OpenEdition}

\section{Journals}

Edição electrónica

URL: http://journals.openedition.org/rccs/249

DOI: $10.4000 /$ rccs. 249

ISSN: $2182-7435$

\section{Editora}

Centro de Estudos Sociais da Universidade de Coimbra

\section{Edição impressa}

Data de publição: 1 Setembro 2009

Paginação: 123-144

ISSN: 0254-1106

\section{Refêrencia eletrónica}

Hermes Augusto Costa, «A flexigurança em Portugal: Desafios e dilemas da sua aplicação », Revista Crítica de Ciências Sociais [Online], 86 | 2009, colocado online no dia 01 dezembro 2012, criado a 03 maio 2019. URL : http://journals.openedition.org/rccs/249 ; DOI : 10.4000/rccs.249 


\title{
HERMES AUGUSTO COSTA
}

\section{A flexigurança em Portugal: Desafios e dilemas da sua aplicação*}

\begin{abstract}
Este texto avalia alguns dos impactos provocados no mercado laboral português pela introdução do tema da flexigurança neste país. Tendo por referência o Livro Verde da Comissão Europeia, são discutidos os conteúdos e propósitos da flexigurança e testadas algumas das características do "modelo dinamarquês", normalmente tido como exemplo a seguir. Com base na análise de vários exemplos reveladores de situações de vulnerabilidade face ao mercado de trabalho, conclui-se serem maiores os sinais de inadequação da flexigurança ao contexto português do que as virtualidades desta medida política deliberada.
\end{abstract}

Palavras-chave: flexigurança; Livro Verde; mercado de trabalho; Portugal.

\section{Introdução}

Em especial nos últimos 4 anos, as reflexões relativas aos "desafios da flexigurança" confrontaram conjuntamente os sistemas de relações laborais europeus. Enquanto medida política deliberada, a flexigurança teve o condão de perspectivar o modo como os mercados de trabalho europeus se podem ajustar aos objectivos gizados pela Estratégia de Lisboa (2000): crescimento sustentável, com mais e melhores empregos. Na verdade, o desafio da flexigurança inscreve-se, em larga medida, na estratégia europeia para o emprego, sendo compatível com a orientação da Comissão Europeia na área da política económica e social em geral e da política de emprego em particular. Para Keune e Jepsen (2007: 9-12), a flexigurança apresenta-se

\footnotetext{
* Este texto é uma versão actualizada de várias conferências que apresentei sobre o tema, nomeadamente: no seminário internacional Modernizar o direito no trabalho para enfrentar os desafios do século XXI - Portugal face ao Livro Verde da Comissão Europeia, Lisboa, Fundação ISCTE, 27 de Março de 2007; ao abrigo do projecto internacional, apoiado pelo CNPQ, Mudanças no Mundo do Trabalho e Novas Políticas Públicas, Universidade Federal de Campina Grande e Universidade Federal da Paraíba, 28 e 31 de Agosto de 2007; no âmbito do II Curso da Cooperativa Culturas do Trabalho e Socialismo, subordinado ao tema Capitalismo global: precariedade e flexigurança, Lisboa, Biblioteca do Museu da República e Resistência, 9 de Fevereiro de 2008.
} 
compatível com o papel da Comissão enquanto: i) disseminadora das "melhores práticas" (não foi por acaso que os exemplos da Dinamarca e da Holanda - países onde, em 2005, as mais elevadas taxas de emprego se registaram na população entre 15 e 64 anos, respectivamente $75,9 \%$ e $73,2 \%$ foram tidos como os principais casos nacionais associados ao conceito de flexigurança); ii) conciliadora de interesses (por exemplo através do apoio ao diálogo social europeu e sectorial e ao envolvimento dos parceiros sociais nacionais na concepção e implementação de políticas de emprego); iii) promotora de um discurso assente no modelo social europeu, bem como na relação entre competitividade e coesão social (recorde-se, por exemplo, que a Estratégia de Lisboa se baseou num compromisso da União Europeia com um tipo de capitalismo europeu, em oposição ao capitalismo americano, preocupado com o reforço do papel dos mercados e do crescimento económico, mas ao mesmo tempo um capitalismo de compromisso com objectivos de pleno emprego e reforço da coesão social).

Ao lançar, no final de 2006, o documento intitulado Livro Verde. Modernizar o direito do trabalho para enfrentar os desafios do século XXI (Comissão das Comunidades Europeias, 2006), a Comissão Europeia, não obstante o seu papel de mediadora de diferentes interesses, criou condições, desde então, para o desencadear de debates entre os principais actores do mercado laboral (representantes patronais e sindicais). Os ecos do documento acabariam igualmente por fazer-se ouvir, no caso português, no seio de organizações partidárias e, inclusive, entre os próprios académicos responsáveis pela elaboração do Livro Branco das Relações Laborais (Dezembro 2007), documento que "preparou" as alterações posteriores à legislação laboral portuguesa.

O propósito deste texto não é, todavia, o de analisar o modo como alguns dos princípios orientadores da flexigurança acabariam por ser vertidos no Código do Trabalho (Lei 7/2009, de 12 de Fevereiro), transposição essa que acabou por ser feita preferencialmente por meio da noção de "adaptabilidade". Pretende-se, antes, elencar e problematizar um conjunto de pontos associados à flexigurança (tendo o Livro Verde da Comissão Europeia como ponto de partida) e ao modo como eles se afiguram adequados ou inadequados à realidade portuguesa.

A primeira secção apresenta breves considerações sobre os significados da noção de "flexigurança" e recupera alguns dos pontos positivos e negativos emanados do Livro Verde da Comissão Europeia. Depois são assinaladas algumas características do "modelo dinamarquês" de flexigurança (o mais citado quando se aborda o tema em Portugal). Por fim são recuperados alguns estudos realizados em Portugal (ou tendo Portugal e a Dinamarca 
como referências) com o intuito de "pôr à prova" os vértices do "triângulo dourado" em que assenta a flexigurança dinamarquesa: mercados de trabalho flexíveis, sistemas de bem-estar fortes e políticas activas do mercado de trabalho.

\section{O sentido geral da flexigurança e os mais e menos do Livro Verde}

Grosso modo o termo "flexigurança" (tradução literal da expressão flexicurity) sugere, em termos teóricos, que estamos diante de um instrumento que visa atribuir segurança aos indivíduos no seio de mercados de trabalho flexíveis, permitindo diferentes trajectórias profissionais e estilos de vida (Wilthagen e Tros, 2004), e que parece buscar um equilíbrio entre uma flexibilidade sensível às preocupações das empresas e uma flexibilidade capaz de garantir a protecção do trabalho de acordo com critérios de justiça social. Nestes termos argumenta-se, por exemplo, que só flexibilizando a legislação do trabalho e as condições em que este é prestado se podem conseguir mais empregos para mais pessoas.

Assim sendo, se bem aplicada, a flexigurança seria indutora de uma dupla protecção: por um lado protecção aos empregadores, conferindo-lhes a possibilidade de melhor gerirem os recursos humanos que têm ao seu dispor (dispensando trabalhadores incapazes de se ajustarem à evolução do mercado em que se insere a empresa, ou contratando trabalhadores mais bem preparados e qualificados); por outro lado protecção aos trabalhadores, conferindo-lhes mais oportunidades de integração social em situação de desemprego. Nos termos da classificação proposta por Andranik Tangian (2007: 554-555), a flexigurança significa flexibilização (ou desregulação) dos mercados de trabalho com uma "face humana", isto é, compensando e atribuindo vantagens sociais aos grupos mais vulneráveis. Mas a flexigurança distingue-se da desregulação incondicional pelo facto de introduzir mecanismos de compensação na activação da segurança social e do emprego. ${ }^{1}$

Ora, mesmo sem ser inovador face ao discurso académico sobre o assunto, o Livro Verde teve, com efeito, o condão de suscitar a discussão em torno da necessidade de promover a flexigurança, tendo como pano de fundo a construção de um mercado de trabalho flexível e inclusivo (pp. 7-10). $\mathrm{O}$ facto de lançar um conjunto amplo de questões para debate sobre a

\footnotetext{
${ }^{1}$ Para uma análise dos vários significados téoricos e políticos da flexigurança, cf., entre outros, os artigos contidos no número temático da revista Transfer (2004), Dornelas et al. (2006: 185-196), Eurofound $(2007 ; 2008)$, Commission of the European Communities (2007), Silva (2008), Ferreira (2007; 2008a; 2008b), Tangian (2007), Muffels e Luijkx (2008).
} 
modernização do direito laboral foi, por si só, outro sinal mais do documento, pois suscitou a discussão imediata entre parceiros sociais.

Outra das questões que conferiu positividade à flexigurança suscitada pelo Livro Verde (p. 11) foi a proposta de conjugação da legislação em matéria de protecção do emprego mais flexível com um auxílio mais estruturado aos desempregados (seja sob a forma de compensação de rendimento/políticas passivas, seja sobre a forma de políticas activas). Este ponto sugeria, desde logo, uma gestão equilibrada entre a óptica do legislador e a perspectiva dos actores sociais (ainda que sem garantir automaticamente o entendimento entre estes). Ou seja, abria-se a possibilidade teórica da criação de um "ponto de equilíbrio" entre uma dimensão objectiva das políticas e uma dimensão subjectiva dos actores por elas visados.

Por outro lado, o facto de se prever a possibilidade de criação de um "sistema básico de direitos" aplicável a todos os trabalhadores, independentemente do contrato de trabalho que possuem (p. 14/questão 8 do Livro Verde), faria particular sentido, sobretudo se funcionasse também como uma espécie de sinal de "alerta" para as importantes convenções da OIT (liberdade sindical, direito à negociação colectiva, igualdade de remuneração, luta contra a discriminação no emprego e na profissão, proibição do trabalho infantil e do trabalho forçado) que, como é sabido, são ainda recorrentemente desrespeitadas. Aliás, diga-se que esta questão parece relacionar-se com uma outra que se reveste de grande importância: a questão 12 (p. 16 do Livro Verde), nos termos da qual se indaga sobre a possibilidade da constituição de uma noção de "trabalhador" transnacionalmente uniforme. Trata-se de uma ambição certamente difícil de concretizar, em especial em resultado da diversidade de regimes jurídicos e condições de trabalho dos sistemas nacionais de relações laborais. No entanto a sua concretização afigura-se necessária, pois, independentemente do Estado-membro, a figura do "trabalhador" deveria pelo menos ser reconhecida como a de um sujeito portador de direitos, o que nem sempre acontece.

Um outro ponto cuja problematização é oportuna prende-se com a maior ou menor autonomia de que cada trabalhador dispõe face à sua situação de emprego (ver nas pp. 8-9 do Livro Verde as considerações a propósito do trabalho por conta própria). A utilidade dessa discussão é grande, já que está por fazer um estudo aprofundando na sociedade portuguesa sobre a relação entre autonomia e segurança, que permitisse perceber se mais autonomia sobre as condições de emprego se traduz em níveis mais elevados de insegurança em matéria de protecção social ou se o inverso (menor autonomia de condições de emprego gera maior segurança em matéria de protecção social) pode igualmente ocorrer. 
Não obstante estes sinais positivos sobressaem no Livro Verde, em meu entender, vários aspectos criticáveis que, em parte, acabariam por servir de pretexto para marcar a posição crítica das organizações sindicais portuguesas (em especial da CGTP $)^{2}$ ao documento e a discussão que viria a seguir-se. Esses aspectos negativos do Livro Verde podem sistematizar-se:

- na notória subalternização do "trabalhador" face ao empregador (o que se reflecte, por exemplo, na ausência de referências à Confederação Europeia de Sindicatos, por sinal a maior organização europeia representativa de trabalhadores);

- no olhar demasiado benévolo que é veiculado sobre a globalização;

- na apresentação de uma visão demasiado centrada no ponto de vista das políticas e pouco atenta ao ponto de vista dos actores, embora fosse importante demonstrar (na linha do sugerido anteriormente) sinais claros de uma visão equilibrada entre o ponto de vista (objectivo) das políticas e a perspectiva (subjectiva) dos actores do mercado de trabalho;

- no escasso espaço dedicado à organização do tempo de trabalho (p. 15 do Livro Verde); na sociedade portuguesa, a gestão do tempo de trabalho foi uma das questões que produziu impactos significativos sobre as relações laborais ao longo da última década, ao desafiar o primado da lei e a sua aplicação (Ferreira e Costa, 1998/99: 191), tendo como referência, por exemplo, a "batalha" suscitada pela "Lei das 40 horas" (em 1996);

- no facto de, apesar de se reconhecer explicitamente a dicotomia insiders/outsiders ("mercado de trabalho primário"/"mercado de trabalho secundário"), não se dar conta especificamente do problema da economia informal (o que talvez apenas se compreenda na medida em que o que é "clandestino" não é declarado!), problema em crescimento nos países subdesenvolvidos, mas igualmente nos países desenvolvidos ou em desenvolvimento.

Registe-se também (continuando ainda num registo crítico e regressando ao sentido geral da flexigurança) que algumas das dicotomias que têm vindo a ser utilizadas acabam por revelar a relativa fragilidade conceptual das fronteiras que a flexigurança anuncia. Uma dessas dicotomias é a dicotomia emprego "mau"/desemprego "bom". Reconhecendo que estamos diante de

\footnotetext{
${ }^{2}$ Sobre as posições iniciais das organizações sindicais nacionais e europeias produzidas na sequên-
} cia do Livro Verde, cf., entre outros, CGTP (2007), UGT (2007) ou ETUC (2007a; 2007b). 
uma dicotomia "cínica" (pois confere "negatividade" ao emprego enquanto ideal e "positividade" ao desemprego enquanto chaga das sociedades), em Portugal parece prevalecer a lógica da salvaguarda do emprego, sendo este considerado por quem trabalha como preferível (mesmo que mal pago, realizado em condições de precariedade, sem estímulos de mobilidade, etc.) do que o desemprego, do qual se desconfia e face ao qual se criam distanciamentos e se levantam suspeições mesmo que rotulado de "bom". Observem-se, por exemplo, as situações em que se colocam os trabalhadores das multinacionais a operar em Portugal e que, nos últimos anos, perderam os seus postos de trabalho em virtude de processos de deslocalização e encerramentos totais ou parciais: a Clarks, do sector do calçado, em 2003; a Honeywell, do sector metalúrgico, em 2005; a General Motors (Opel), do sector metalúrgico (automóvel), em 2006; a Alcoa (cablagens eléctricas), em 2007; etc. Em qualquer dos casos citados parecem estar por demonstrar os efeitos benéficos da situação de desemprego em que caíram milhares de trabalhadores (e, note-se, estou a apenas a reportar-me ao universo da multinacionais, cuja expressão no tecido produtivo português é, como se sabe, diminuta, quando comparada com a preponderância das pequenas e médias empresas).

Ante um olhar mais prudente e desconfiado sobre os desafios da flexigurança, importaria então perguntar o seguinte: que condições existem no mercado de trabalho em Portugal para que a flexigurança possa passar de valor desejável (cujos méritos teóricos estão identificados e são incentivados politicamente) a valor desejado (efectivamente assumido por todos os intervenientes no mercado de trabalho como uma inovação a abraçar com êxito)? Tendo presente esta interrogação, abordarei seguidamente algumas características do "modelo dinamarquês" de flexigurança, questionando posteriormente a sua efectividade no contexto português.

\section{Características do "modelo" de flexigurança}

A introdução do debate sobre a flexigurança em Portugal fez-se, quase invariavelmente, tendo por comparação o caso dinamarquês. É desse exemplo que parto aqui também para, em paralelo, ir traçando alguns elementos de comparação com a realidade portuguesa. Apoiando-me no trabalho de síntese sobre o "modelo dinamarquês" proposto por Madsen (2004), elenco em seguida as características da flexigurança praticadas neste país, por sinal características que tornariam teoricamente exportável o referido modelo.

- Trata-se de um país com 5,4 milhões de habitantes, que apresenta uma das mais elevadas protecções sociais do mundo e uma taxa de desemprego 
relativamente baixa, ainda que com tendência recente de crescimento acentuado. ${ }^{3}$

- É grande a facilidade de despedimento concedida às empresas (nalgumas convenções colectivas é preciso apenas um pré-aviso de 5 dias), sendo que o Estado assegura aos desempregados indemnizações e rendimentos sociais por um largo período, garantindo-lhes ainda acompanhamento na procura de trabalho e proporcionando-lhes reformas antecipadas (apesar do país ter uma das taxas de actividade mais elevadas da população com mais de 60 anos).

- Apesar disso o intervencionismo do Estado é considerado fraco: o governo não determina o salário mínimo, não enquadra o direito de greve, não limita os direitos das empresas quanto a despedimentos e contratações e não as obriga a pagarem indemnizações de despedimentos. O Estado também não impõe um limite legal ao tempo de trabalho, pois o mercado de trabalho é regulado (como na Suécia e na Finlândia) por acordos colectivos ou de empresa, negociados entre sindicatos (poderosos) e patronato.

- Em caso de despedimento um dinamarquês tem direito a cerca de $96 \%$ do seu salário durante 4 anos. ${ }^{4}$ As indemnizações e os subsídios de desemprego são pagos por caixas privadas, geridas pelos sindicatos e alimentadas por eles e pelo Estado. Nos 6 meses seguintes ao despedimento o desempregado participa numa formação profissional obrigatória, paga pelo Estado. Após este período deve procurar emprego activamente, sendo apoiado pela administração pública nesse esforço. Em contrapartida, quem recusar uma oferta de "emprego conveniente" perde o direito ao subsídio. Neste contexto, a duração média do desemprego ronda os 6-7 meses.

- O sindicalismo apresenta uma força assinalável, testemunhada pelos $80 \%$ da população activa que se encontra sindicalizada. Assim sendo, aderir a um sindicato não constitui propriamente uma escolha política (como em Portugal), mas uma questão de bom senso (uma espécie de vocação

\footnotetext{
${ }^{3}$ Segundo o Eurostat, em Junho de 2009 a taxa de desemprego neste país situava-se nos 6.2\% (valor semelhante ao registado em 2004), invertendo uma tendência de baixa que chegou aos 3,1\% em Junho de 2008. Ainda assim, no contexto ainda adverso da conjuntura internacional, aquele país nórdico apresenta desempenhos claramente positivos face ao desemprego na Zona Euro (situado nos 9,4\%) e na UE-27 (situado nos $8.9 \%$ ) e face ao que sucede em Portugal (com valores de desemprego de $9,3 \%$ ).

${ }^{4}$ Em Portugal, o montante do subsídio corresponde a cerca de 65\% do salário bruto.

5 Esta noção de "emprego conveniente" parece já ter sido "importada" em Portugal, pois em 2007 passou a ser parte integrante do Guia Prático relativo ao subsídio de desemprego, acabando por funcionar como uma espécie de "condicionalidade negativa", já que sujeita os beneficiários à obrigação de aceitar eventuais ofertas de emprego em actividades distintas das suas (ainda que os Centros de Emprego devam levar isso em consideração), mais mal pagas e distantes de casa, sob pena de perderem o subsídio.
} 
natural): os sindicatos gerem as caixas de subsídios de desemprego, pagam as reformas antecipadas e negoceiam as condições laborais por sector.

- Na Dinamarca a diferença entre os salários mais baixos e os mais altos é de 1 para 10 (em França é 1 para 500 ou para 1000). ${ }^{6}$

- O "modelo dinamarquês" assenta numa cultura de compromisso e consenso entre actores sociais, ao passo que em Portugal vigora no mundo do trabalho uma cultura de conflito e de relações de força, marcada por sentimentos de medo e laços de dependência (Estanque e Costa, 2007: 4).

- Dir-se-ia que o principal contra reside no facto de os dinamarqueses pagarem, em média, $50 \%$ de impostos e o IVA rondar os $25 \%$. No entanto, tal acaba por não ser um verdadeiro senão, pois a metade que lhes resta de salários parece ser suficiente para lhes permitir viver desafogadamente.

\section{O "triângulo dourado" da flexigurança posto à prova}

Algumas das características do "modelo dinamarquês" parecem ir ao encontro dos desafios associados às reformas dos Estados Europeus em matéria de emprego, a saber: por um lado, apostar em mais flexibilidade dos mercados de trabalho; por outro lado, estimular uma reorientação das políticas de emprego de uma filosofia de atribuição de subsídios/compensações pela perda de emprego (políticas passivas) para uma filosofia assente na promoção de novas oportunidades de emprego (políticas activas), com o propósito de reduzir a dependência dos subsídios por parte dos desempregados e os gastos com os orçamentos da segurança social (Hespanha e Møller, 2001: 56). Ora, pelo exposto acima, parece feliz a síntese segundo a qual o "triângulo dourado" da flexigurança na Dinamarca se inscreve naquela tendência, ao assentar em três vértices: i) um mercado de trabalho flexível; ii) generosos sistemas de bem-estar; iii) políticas de mercado de trabalho activas (Madsen, 2004: 189). ${ }^{7}$ É este triângulo que vale a pena pôr à prova no confronto com a realidade portuguesa.

No que diz respeito ao vértice relativo ao mercado de trabalho flexível, importa desde logo tecer algumas considerações. Na verdade, o debate sobre rigidez versus flexibililidade do mercado de trabalho, que aparece subjacente à discussão da flexigurança, não suscitou consensos nem entre

\footnotetext{
${ }^{6}$ Em Portugal, por exemplo, o desnível salarial entre administradores e restantes trabalhadores é abismal e vários estudos têm dado testemunho disso: só para dar um exemplo, no Grupo Portugal Telecom o salário médio mensal de um administrador executivo ascende a $185.590 €$, ao passo que o custo médio por trabalhador é de 1.449€ (Visão, 10.01.2008, p. 30).

7 O Livro Verde da Comissão Europeia fez igualmente assentar a dimensão política da flexigurança em princípios próximos desses: i) aprendizagem ao longo da vida; ii) políticas activas do mercado de trabalho; iii) e regras mais flexíveis no domínio da segurança social (Comissão das Comunidades Europeias, 2006: 4).
} 
patrões e sindicatos, nem entre os próprios especialistas portugueses na matéria. Se, por um lado, se apontou para um elevado grau de rigidez formal da legislação laboral portuguesa, ${ }^{8}$ por outro lado foi igualmente reconhecido que o mais relevante não seria a legislação em si mesma, mas o uso que dela é feito e as consequências da sua aplicação. $\mathrm{Na}$ verdade, a capacidade de regulação da legislação é apresentada como variável: primeiro, porque a litigância varia por país, região, sector, profissão, situação na profissão ou situação no mercado de emprego; segundo, porque é diverso o papel atribuído à lei, às práticas de participação ou às convenções colectivas em cada sistema de emprego; finalmente, porque as avaliações baseadas somente na letra das normas sobre a liberdade patronal para contratar e despedir não levam em conta o conjunto, mas tão-só as condicionantes ao poder patronal nos momentos de início e de termo da relação laboral. Assim sendo, não deixaria de ser crucial ter igualmente em conta a atipicidade do emprego, as formas de emprego oculto e o peso dessas formas no conjunto do emprego total (Dornelas et al., 2006: 186-187).

O Livro Branco das Relações Laborais (LBRL, Dezembro 2007) veio, de certo modo, pôr de novo ao rubro esta tensão entre flexibilidade e rigidez, nomeadamente ao realçar a falta de flexibilidade sobretudo ao nível das empresas e não tanto do mercado de trabalho. Com efeito, no que concerne ao mercado de trabalho em Portugal, em cada 3 meses verifica-se uma média de cerca de 300.000 pessoas (cerca de 10\% do emprego total) afectadas por uma dinâmica de criação e destruição de emprego. Por trimestre criam-se 5,3\% de empregos novos e destroem-se 5,1\% (AAVV, 2007: 25). ${ }^{9}$ Por outro lado ainda, em Portugal, país onde em cada ano 1,1 milhões de indivíduos mudam de situação no mercado de trabalho (AAVV, 2007: 20), por cada emprego criado há uma rotação de cerca de 2 trabalhadores, ao passo que nos EUA essa rotação é de cerca de 3 trabalhadores (AAVV, 2007: 32).

No que diz respeito às empresas e aos trabalhadores, a Comissão do LBRL identificou sinais de rigidez. Como exemplo da falta de flexibilidade

\footnotetext{
${ }^{8}$ Para o efeito, é recorrentemente utilizado o indicador da Legislação da Protecção do Emprego (LPE), nos termos de uma avaliação proposta pela OCDE, segundo a qual, no caso português, além dos limites à contratação temporária e da dificuldade em realizar despedimentos colectivos, é sobretudo manifesta a dificuldade em despedir trabalhadores com empregos sem termo (Dornelas et al., 2006: 186).

${ }^{9}$ No quadro da UE a 25 também essa flexibilidade do mercado de trabalho é assinalada: se entre $3 \%$ a $4 \%$ dos empregos são destruídos, entre $5 \%$ a $8 \%$ de novos empregos são criados anualmente (ETUC/BUSINESSEUROPE/UEAPME/CEEP, 2007: 16). Para a Confederação Europeia de Sindicatos, a flexibilidade já é muito elevada em muitos Estados-membros, receando-se que uma tendência para maior flexibilização geradora de mais despedimentos e cessação de diversas formas de relações contratuais possa vir a sair vencedora (ETUC, 2007b).
} 
nas empresas, sustentou-se que Portugal é o segundo país da UE (atrás do Chipre) onde a regularidade dos horários diários é maior: a média da UE-25 situa-se nos $37 \%$, ao passo que em Portugal se situa nos $80 \%$. Apenas $10 \%$ dos portugueses não trabalham nos mesmos dias de semana e 16,4\% não têm hora fixa de entrada e saída no emprego. Além disso apenas $12 \%$ dos portugueses trabalham por turnos, quando a média na UE-25 é de 19,4\% (AAVV, 2007: 56). Quanto à baixa flexibilidade dos trabalhadores, o caso português foi apresentado como um dos que apresenta valores mais baixos de adaptabilidade funcional, pois apenas $31,9 \%$ dos trabalhadores executam rotação de tarefas, ao passo que a média europeia ronda os $50 \%$. Por outro lado, quando se questionou os trabalhadores portugueses sobre o facto de a rotação de tarefas exigir competências e aptidões profissionais diferentes, apenas $65,4 \%$ referiram essa exigência, contra $80,7 \%$ na UE-15, ao passo que em países como a Holanda e a Dinamarca essa exigência se situa acima dos 90\% (AAVV, 2007: 66).

Tendo em conta estes dados, parece efectivamente ter sido sobretudo nesta rigidez (das empresas e dos trabalhadores) que os responsáveis do LBRL se apoiaram para propor maior flexibilidade nas empresas, simplificação dos despedimentos, maior favorecimento dos contratos individuais, entre várias outras medidas. Como referi inicialmente, não pretendo aqui fazer a discussão do modo com essas e outras propostas foram juridicamente vertidas no actual Código do Trabalho. Elas terão servido, no entanto, para tentar dar vida à flexigurança no seio das leis do trabalho, ainda que, a meu ver, mais pareçam conferir visibilidade a um registo de flexibilidade e invisibilidade a um registo de segurança face a uma relação de emprego.

O segundo e terceiro vértices da flexigurança dinamarquesa (respectivamente generosos sistemas de bem-estar e políticas de mercado de trabalho activas) podem analisar-se conjugadamente. Relativamente ao segundo vértice, de certo modo já antes me reportei a ele quando abordei as características do "modelo dinamarquês". Constata-se que os sistemas de bem-estar portugueses estão muito aquém dos padrões de bem-estar daquele país nórdico. Como diriam Gallie e Paugam (2000), é possível identificar vários regimes de protecção: sub-protector; liberal-mínimo; centrado no emprego; universal. O português inclui-se na Europa do Sul e é classificado como sub-protector: a protecção aos desempregados depende da sua participação no mercado de trabalho; abrange um número reduzido de desempregados; oferece aos desempregados um nível mínimo de protecção; investe pouco em políticas activas de emprego; abre uma grande margem para que os desempregados sejam confrontados com dificuldades económicas graves ou vivam abaixo do limiar de pobreza; favorece uma elevada 
probabilidade de desemprego prolongado. Segue-se assim, na acepção de Muffels e Luijkx (2008: 225), uma tradição do Mediterrâneo/do Sul, onde se combinam baixos níveis de flexibilidade com baixos níveis de segurança de emprego/rendimento, baixa empregabilidade e maior presença de políticas passivas do mercado de trabalho.

Mas importa olhar para alguns estudos realizados envolvendo a realidade portuguesa que põem em destaque aqueles dois vértices do triângulo e que dão testemunho de situações de vulnerabilidade face ao mercado de trabalho. Um dos grupos-alvo do desemprego capaz de pôr à prova a flexigurança e, portanto, testar em que medida se poderiam encontrar soluções "boas" em situação de desemprego, é o dos desempregados de meia-idade, situados na barreira dos 45 anos (i.e., com idade a mais para arranjar trabalho mas ao mesmo tempo sem idade suficiente para a reforma). Ao estudar esse grupo de desempregados numa empresa de cerâmica que encerrou (a Estaco), Pedro Araújo (2008) analisou o tipo de protecções e recursos conferidos (principalmente pelo Estado) aos desempregados e/ou mobilizáveis por eles (através das suas redes sociais) para fazer face à privação de emprego. Em concreto, tomou como objecto da sua análise vários mediadores de compensação: o Estado Social (enquanto garante de protecção na eventualidade de desemprego, por meio do recurso a medidas de reparação na eventualidade de desemprego, passivas e activas) ${ }^{10}$, a sociedade-providência (e as esferas de sociabilidade a ela associadas) ${ }^{11}$ e actividades de substituição (que revelam a capacidade e o dinamismo dos agentes na busca de respostas, que se podem articular com o mercado, com o Estado Social e com a própria sociedade-providência). ${ }^{12}$

\footnotetext{
${ }^{10}$ De entre as medidas de reparação do desemprego (Decreto-Lei no 119/99, de 14 de Abril), destacam-se as passivas (subsídio de desemprego; subsídio social de desemprego) e activas (criação do próprio emprego; subsídio de desemprego parcial; cursos de formação avançada; programas de ocupação de desempregados/POCs).

${ }^{11}$ Nomeadamente a esfera primária (agregado familiar e família mais próxima), secundária (amigos, vizinhos e membros da família fora do agregado familiar), terciária (participação em organizações e/ou associações). A este respeito são inevitáveis comparações com o caso dinamarquês, onde é notória uma maior desinstitucionalização da família, ao contrário de Portugal, onde parece mais evidente a presença de um modelo tradicional de família, não obstante algumas alterações na estrutura familiar poderem interferir com a "eficácia" da sociedade-providência (ex.: nuclearização dos agregados familiares; recomposição dos papéis dentro da família; aumento da monoparentalidade; declínio das organizações da comunidade ligadas à sobrevivência material, tais como, mutualismo, entreajuda, associativismo laboral; cf. Hespanha e Portugal, 2002: 126).

${ }_{12}$ São actividades: 1) que se podem realizar à margem do mercado de trabalho (no domínio da “economia informal”); 2) que consistem num retorno a actividades anteriormente desenvolvidas em paralelo à actividade principal, numa lógica de diversificação económica e/ou na prestação de serviços dentro e fora do agregado doméstico;3) que são desenvolvidas na perspectiva de regressar diferentemente ao mercado de trabalho (por exemplo, através da frequência de acções de formação profissional; da criação do próprio emprego; da entrada numa actividade completamente nova,
} 
A questão que, consequentemente, se impunha era saber de que forma se socorreram os desempregados da empresa encerrada dos mediadores de compensação, para fazer face à situação de desemprego.

Face ao mediador de compensação Estado Social, Pedro Araújo (2008: 99-110) constatou que os desempregados não arriscaram pôr em causa a "estabilidade" que representam as prestações de desemprego, não optando por um regresso ao mercado de trabalho em condições precárias ou mesmo para criar o próprio emprego. Assim sendo, as estratégias dos desempregados passaram pela tentativa de maximizar o período de abrangência das protecções sociais. Ou seja, tratou-se de estratégias orientadas para os mecanismos institucionais de apoio aos desempregados, cuja acção se resumiu ao cumprimento das suas obrigações legais e à sua função redistributiva. Com o prolongamento do desemprego, o mercado revelou-se uma meta cada vez mais inatingível, pelo que foi ao Estado Social que se atribuiu a responsabilidade de garantir o apoio material sonegado pela falência da empresa.

Face ao mediador de compensação redes sociais, observou-se que este não era suficiente para proporcionar aos desempregados vivências do desemprego mais autónomas. Pelo contrário, quando não articuladas com as compensações financeiras providenciadas pelas medidas de reparação estatais, as redes reforçavam ainda mais o sentimento de perda de autonomia. E uma vez que o desemprego ocorre no seio da família nuclear, isso significa que as solidariedades familiares são geradas quase exclusivamente entre os membros do casal. No caso das mulheres - a quem é reconhecido o papel especial de assegurar o funcionamento de redes sociais (Portugal, 2006) -, o desemprego tolhe claramente as condições de funcionamento dessas redes (Araújo, 2008: 114).

Por fim, face ao mediador de compensação actividades de substituição, Araújo (2008: 115-127) conclui que as prestações de desemprego são mais seguras do que a realização de actividades do tipo não declarado e que as actividades anteriormente desenvolvidas em paralelo à actividade principal assumem particular destaque - como sejam a pequena agricultura para os homens e o cuidado a crianças para as mulheres. A pequena agricultura continua a desempenhar um efeito de compensação das prestações de desemprego, ao passo que o cuidado das crianças (dos netos, na maioria dos casos) suscita situações ambíguas: de sentido positivo, por um lado, na medida em que

por meio de reconversão profissional, desempenhando aqui o Estado um papel fundamental, através da introdução de medidas de reparação do desemprego activas); 4) que são de fraca vinculação ao mercado de trabalho (modalidades de trabalho flexível), na linha do que Kovács (2005) designou de flexibilidade precária estável, assente em: percursos caracterizados por mudanças frequentes de empregos flexíveis, na maioria precários. 
permite "esquecer" a falência da empresa; de sentido negativo, por outro lado, já que a falência da empresa reduziu as possibilidades de auxílio financeiro.

A partir do estudo acima sintetizado pode, pois, concluir-se que é sobretudo o Estado, mesmo sendo sub-protector, que se assume como elemento central na protecção dos desempregados, aparecendo as redes sociais e as actividades de substituição como protecções complementares e muitas vezes precárias. Assim sendo, de que flexigurança falamos, se em situações de particular instabilidade e insegurança, decorrentes do desemprego é ao Estado que se atribui a responsabilidade para assegurar a autonomia aos desempregados? Em meu entender, os mediadores de compensação do desemprego parecem ser indutores do que poderia designar-se de flexigurança defensiva ou passiva, pois apenas se contribui para reduzir riscos sociais e não propriamente para estimular estratégias activas e autónomas, capazes de potenciar uma nova relação de emprego para quem ainda não chegou ao fim da vida activa, apesar da longa experiência profissional anterior.

A questão das políticas activas do mercado de trabalho (outro dos vértices do triângulo da flexigurança) parece, pois, não ter sido contemplada no exemplo acima mencionado, ou foi relegada para um plano secundário. Essa questão foi igualmente objecto de outros estudos envolvendo a realidade portuguesa e dinamarquesa. Hespanha e Møller (2001), por exemplo, analisaram dois tipos de políticas: políticas associadas ao "mercado de trabatho secundário" e políticas associadas a educação e formação.

No caso das primeiras, a análise incidiu sobre programas de activação com o propósito de incluir desempregados, temporários ou permanentes, nalgum tipo de trabalho pago. Na Dinamarca contemplou-se: o job training com empregadores públicos e privados; o individual job training, que envolve trabalho temporário; pool jobs, empregos no sector público até 3 anos de duração para as pessoas desempregadas durante 1 ano. Em Portugal contemplaram-se sobretudo os programas de ocupação de desempregados (POCs), que implicam realização de estágios promovidos por organizações não-lucrativas e que, como é sabido, visam combater a desmotivação e as tendências de marginalização entre os desempregados e promover a sua inclusão através de ocupações sociais úteis.

No caso do segundo tipo de políticas, na Dinamarca, o estudo centrou-se em desempregados que recebiam treino para prosseguirem cursos de educação ou participarem em programas de formação. Em Portugal, focou um grupo de mulheres (algumas das quais a receber o então designado Rendimento Mínimo Garantido) que participaram em programas de formação direccionados para pessoas desempregadas com baixos níveis de educação. 
O que aquela investigação permitiu apurar foi a existência de distintos sistemas de inclusão/exclusão ou, se preferirmos, diferentes condições de problematização da aplicação da propalada flexigurança nos dias de hoje. Ao terem em conta cinco critérios para aferir essa inclusão/exclusão (trabalho, rendimento e consumo, redes sociais, política e lazer) o estudo apurou o seguinte:

i) quanto ao trabalho, se para os dinamarqueses o trabalho pago é um elemento central da sua vida, para os portugueses esse sentimento reforça-se ainda mais, pois o trabalho é visto como fonte de realização e forma de ganhar dinheiro; a participação na esfera económica é considerada a mais importante;

ii) quanto à variável rendimento e consumo, os dinamarqueses inseridos em programas de activação expressam satisfação com os seus padrões de vida e não estão preocupados com os problemas económicos futuros, ao passo que os portugueses "activados" apresentam baixos níveis de rendimento e débeis padrões de consumo;

iii) a influência das redes sociais (no local de trabalho e fora dele) revelou-se particularmente pronunciada no caso português;

iv) quanto à política (avaliação das taxas de participação na política e na vida sindical), entre os dinamarqueses "activados" os índices de participação em organizações partidárias ou sindicais são baixos (3\% e 13\% respectivamente), mas entre os portugueses "activados" os valores são ainda mais baixos, tornando-se evidente uma total desconfiança em relação aos políticos, por exemplo;

v) por fim, quanto ao lazer, verificou-se que quase metade dos dinamarqueses "activados" despende tempo em actividades de lazer, ao passo que os portugueses "activados" expressam limitações no acesso a eventos culturais, sobretudo em função de um conjunto de factores: escassez de rendimento, falta de tempo, regras patriarcais colocadas às mulheres casadas, etc.

Os autores do estudo encontram ainda uma diferença entre a Dinamarca e Portugal no que concerne aos programas de activação: no caso português, o impacto de tais programas é considerado reduzido, ${ }^{13} \mathrm{o}$ que em parte se explica também pelo facto de as organizações sindicais se terem mostrado

\footnotetext{
${ }_{13}$ Mais recentemente, ao reportarem-se a quatro tipos principais de políticas activas do mercado de trabalho - serviços públicos de emprego, formação profissional, medidas de emprego para jovens e subsídio ao emprego -, Centeno e Novo (2008: 155) chegaram a uma conclusão semelhante. Na verdade, ao avaliarem iniciativas implementadas pelos Centros de Emprego, como a medida REAGE (para desempregados com mais de 25 anos e mais de 6 meses de desemprego) e a INSERJOVEM (para jovens com menos de 25 anos e mais de 3 meses de desemprego), concluíram que as medidas incluídas nessas iniciativas revelaram um impacto limitado na redução da duração do desemprego, que atingiu no máximo apenas meio mês.
} 
críticas quanto a possíveis mudanças de orientação tendo em vista reduzir as ainda existentes e "indispensáveis" políticas passivas de emprego (Hespanha e Møller, 2001: 72). No entanto, neste domínio das políticas activas do mercado de trabalho - que a retórica da flexigurança apregoa, mas que em Portugal tem ainda um longo caminho a percorrer - é importante não perder de vista algumas das condições para o seu sucesso. Uma primeira condição passa por reconhecer a heterogeneidade de situações, i.e., reconhecer que a heterogeneidade dos clientes pressupõe uma visão das políticas centrada nos problemas relatados pelos destinatários das políticas, em vez de pressupor que esses problemas são claros (Valkenburg, Lind e Berkel, 2001: 22-23). Um segundo aspecto central passa por garantir que a insegurança (que, no fundo, acaba por estar sempre "escondida" por detrás dos programas de activação) não se converte, findos esses esquemas, numa insegurança redobrada. Por exemplo, é real o risco de as pessoas que passam por estes programas de activação se verem num processo armadilhado, de participação sucessiva, uma após outra, em vários programas de activação (Hespanha e Møller, 2001: 71-72; Valkenburg, Lind e Berkel, 2001: 22). Note-se, aliás, que este é, talvez, o único sinal de assunção de uma mea culpa expressa pelo Livro Verde da Comissão Europeia, quando nele se afirma que se corre "o risco de ver uma parte dos trabalhadores ser apanhada numa sucessão de empregos de curta duração e de baixa qualidade, com uma protecção social insuficiente, que os colocam numa situação vulnerável” (p. 9). Por fim, uma terceira condição passaria por considerar os clientes como "activos" e não "objectos passivos", ou seja, os destinatários deveriam estar motivados para aceitar a activação sob o risco de serem sancionados (Valkenburg, Lind e Berkel, 2001: 23).

Estas condições não escondem, ainda assim, as ambiguidades do próprio discurso da activação. Se, por um lado, se visa materializar direitos sociais básicos, ou mesmo novos direitos sociais como o direito ao trabalho e à integração social, por outro lado a activação é permeável a distorções éticas, financeiras e burocráticas. A relação de proximidade entre os programas de activação e as políticas de subsídios para desempregados condiciona o alcance desses programas, põe em causa a concepção dos planos de activação individual com julgamentos éticos e pode significar que o envolvimento ocupacional dos trabalhadores que recebem subsídio se transforma numa “compulsão para ser activado" (Hespanha e Møller, 2001: 56). Na mesma linha, a flexigurança não se liberta de algumas ambiguidades. Na verdade os discursos da flexigurança são recorrentemente confrontados com práticas de trabalho que, ao mesmo tempo que a enaltecem, a empobrecem de modo evidente. É legítimo portanto questionar em que medida se podem 
fazer convergir ou "flexigurar" de modo uniforme contextos de relações laborais (inclusive os situados num mesmo país) com práticas, esquemas de trabalho, regimes de retribuição, comportamentos patronais ou níveis de qualificação laboral muito diferenciados.

Esta interrogação vem a propósito de uma comparação entre duas conhecidas multinacionais - a Xerox e a Corticeira Amorim - que foi objecto de exposição nalguns media portugueses num passado recente. ${ }^{14}$ Ao comparar-se a situação de trabalho de duas trabalhadoras (uma de cada multinacional) constatava-se o seguinte:

a) enquanto a trabalhadora da Xerox era licenciada em gestão de marketing e vendedora de produto, a trabalhadora da Corticeira Amorim possuía menos qualificações e era controladora de rolhas de cortiça;

b) enquanto a trabalhadora da Xerox, apesar de se encontrar no início da sua vida profissional, ganhava quatro vezes mais e ainda beneficiava de várias regalias sociais (carro, telemóvel, computador, etc.), a trabalhadora da Corticeira Amorim, apesar de trabalhar há mais de 20 anos da empresa, auferia um salário de $527 €$, acrescido de subsídio de refeição;

c) a política social das empresas era igualmente distinta: na Xerox as trabalhadoras beneficiavam de 5 meses de licença de parto (extensível aos pais), 27 dias de férias por ano, duas pontes e o dia de aniversário, creche, ginásio, farmácia, distribuição de fruta fresca pelos locais de trabalho, apoio à vida familiar (se alguém prolongasse o trabalho para lá das 20 horas as luzes desligavam-se automaticamente); ao contrário, na Corticeira Amorim, além daquelas regalias não passarem de um sonho, as trabalhadoras (ou, no caso, a trabalhadora entrevistada) eram obrigadas a estar de pé durante 8 horas, dispunham apenas de uma hora para almoço, tendo ainda por função verificar uma média de 100.000 rolhas por dia, à procura de defeitos.

Em resumo, se virmos bem, a insegurança (se é que existe) da primeira trabalhadora supera as melhores condições de segurança (muito pouco perceptíveis) da segunda. Porventura a única segurança (digna desse nome) que resta a esta última é poder conservar o seu posto de trabalho. Uma eventual perda de emprego desta trabalhadora leva-nos a pensar que a flexigurança a brindaria com uma situação de desemprego "bom" mais vantajosa do que o emprego "mau" que tinha anteriormente.

Os vários exemplos acima mencionados parecem sugerir que a estabilidade continua a ser o ideal inscrito no subconsciente de quem trabalha, como o atesta também a percentagem elevada $(65,6 \%)$ de portugueses que

${ }^{14}$ Cf., por exemplo, a reportagem do Expresso, Revista, 3.03.2007, bem como o artigo de opinião de Miguel Sousa Tavares, Expresso, 10.03.2007. 
expressam uma forte preocupação com a perda do emprego (AAVV, 2007: 84) - i.e., com a perda da segurança e estabilidade associada a uma relação de trabalho. Com efeito, ainda que a flexigurança "prometa" a segurança no desemprego como moeda de troca para a insegurança no emprego, parece ser em situações de emprego que melhor se busca a segurança e não em situações de desemprego.

Isso mesmo se comprovou também noutro estudo junto de representantes portugueses em Conselhos de Empresas Europeus (CEEs, órgãos de informação e consulta de trabalhadores nas multinacionais). Num inquérito aplicado a 42 trabalhadores portugueses eleitos/nomeados representantes em CEEs de multinacionais estrangeiras constatou-se que todos eles possuíam um contrato sem termo. Ou seja, ninguém declarou possuir contrato a prazo, recibo verde, estágio remunerado, estágio não remunerado, etc. Além disso, a estrutura etária dos representantes é maioritariamente de meia-idade (38\% possui entre 41 e 50 anos), seguindo-se o escalão entre os 51 e 60 anos (com $33 \%$ ) e só depois o escalão dos representantes entre os 31 e 40 anos (26\%). Apesar do universo das multinacionais ser bastante volátil, para estes trabalhadores "maduros" não é expectável que a estabilidade que conquistaram ao longo de mais de duas décadas seja agora questionada, e muito menos trocada, por uma suposta (mas na verdade inexistente) estabilidade gerada fora de uma relação de emprego. Assim, a predisposição para a participação em CEEs, bem como em outras organizações de representação laboral, varia precisamente na razão directa da estabilidade e da segurança geradas pela relação de emprego (Costa e Araújo, 2009: 105).

\section{Conclusão}

Enquanto noção teórica, a flexigurança parece ter vindo para ficar, desde logo porque, na sua génese, ela persegue meritórios ideais de justiça e inclusão social, elementos-chave na modernização dos mercados de trabalho. Ainda assim, sendo mais do que uma noção teórica, a flexigurança carece de condições propícias de adaptação aos mercados de trabalho. Nesse sentido, sem negar as virtudes do conceito, ao longo do texto acabei por transmitir sobretudo uma visão crítica da flexigurança em acção, não só porque os actores do mercado de trabalho português conservam evidentes reservas quanto ao seu sucesso, como porque se afigura problemática a sua aplicação ao contexto português, como aqui se procurou demonstrar através da exposição de alguns exemplos de situações de vulnerabilidade face ao mercado de trabalho.

Condenável será certamente se a flexigurança for assumida como mecanismo de facilitação dos despedimentos ou como estratégia de perpetuação 
de empregos precários ou de mudanças frequentes entre empregos precários. Esse receio, sobretudo expresso pelas organizações sindicais, aumenta ao saber-se que, quando combinada com níveis de desemprego elevado, a precariedade de longa duração pode tornar-se igualmente um factor de pobreza. Esta realidade serviria, por si só, para voltarmos aos exemplos. Entre os jovens, mesmo os mais qualificados, as taxas de desemprego estão muito acima da média nacional: segundo o Eurostat, a taxa relativa aos jovens portugueses no primeiro trimestre de 2009 atingiu 19,6\%, sendo cerca de duas vezes superior à taxa total de desemprego, situada nos $9,3 \%$. Por outro lado hoje subsistem, em especial no primeiro emprego, actividades profissionais desinteressantes, que travam o desenvolvimento das qualificações e aprendizagens dos jovens. Esta realidade tem efeitos negativos não só nos planos da insatisfação e do risco de exclusão social, mas também na motivação dos trabalhadores e na produtividade (Estanque e Costa, 2007: 4). Além disso, sectores profissionais aparentemente "livres de perigo" (como os docentes do ensino superior) vão igualmente espreitando os riscos da insegurança: subtracção da exclusividade, abaixamento de categoria, alteração de índices remuneratórios, expansão dos recibos verdes, etc. A revisão dos estatutos das carreiras docente universitária e do pessoal docente do ensino superior politécnico deixará muitos docentes (por sinal alguns com mais de vinte anos de serviço) numa posição particularmente vulnerável face ao mercado de trabalho, representando também um teste à flexigurança.

É justo afirmar que o que está em jogo é a humanização das relações laborais como forma de dignificação do trabalho e, nesse sentido, a valorização dos efeitos de recalibragem sobre os modelos de flexigurança suscitados pela noção de "trabalho digno" (Ferreira, 2008b: 202). Esse desafio humanizador pressupõe que se evite cair na tentação (por vezes perigosamente fácil) de considerar que as múltiplas formas de contratação atípica - contratos a prazo, trabalho temporário, trabalho independente (e falso trabalho independente) ou por conta própria, trabalho a tempo parcial, teletrabalho, trabalho clandestino - sejam vistas, afinal, como "boas referências”. Em especial quando comparadas com outras práticas, nomeadamente as que envolvem mão-de-obra de nacionalidade portuguesa - como é o caso dos milhares de trabalhadores temporários que por ano laboram em regime de "escravatura encoberta" liderada por subcontratadores -, que praticamente tocam ou se confundem com o grau máximo da desumanização. Em última análise persiste no ar a questão de saber de que modo será possível dar oportunidades a múltiplas formas de trabalho (das menos às mais qualificadas) em risco crescente de exclusão. 
Se o argumento dominante da valorização da "produtividade" e da "competitividade" for sinalizado como prioridade, é de admitir que tal não garanta propriamente ao direito do trabalho um impulso modernizador. Ao contrário, se a noção de "trabalhador" for objecto de uma percepção transnacional mais uniforme - como em certa medida o Livro Verde sugeria, ao reportar-se ao caso dos trabalhadores fronteiriços, embora isso também se aplique a comunidades de migrantes e possa estar a ser objecto de protocolos recíprocos entre organizações sindicais de distintos países -, então aí seriam vislumbráveis maiores possibilidades de as relações laborais se imporem como novas e estariam criadas condições para o reforço da noção de "trabalhador cidadão" (Santos e Costa, 2004).

Mas a estratégia política deliberada que subjaz à flexigurança deveria ser adoptada de forma cautelosa e não simplesmente por decreto, pois o mercado de trabalho português e os seus actores (sobretudo das organizações de trabalhadores) só aos poucos vão começando a "digerir" esta questão. Recorde-se uma vez mais que o sucesso da versão dinamarquesa de flexigurança é o resultado de um longo processo histórico, assente numa série de compromissos entre parceiros sociais, a evolução do Estado-Providência e o desenvolvimento gradual de políticas activas para o mercado de trabalho (Madsen, 2004: 206). Além disso, o "modelo dinamarquês" (e holandês) deu provavelmente um bom testemunho da confiança entre as várias partes envolvidas: trabalhadores, sociedade, empresas (Eurofound, 2007: 13); confiança no futuro quanto à necessidade de assumir riscos face ao estatuto do emprego que se tem (i.e., predispor-se a ter empregos mais flexíveis do ponto de vista contratual, temporal e funcional, de modo a combinar trabalho e vida familiar); confiança no sentido das mudanças e na capacidade para se encontrar um emprego equivalente ao que se perdeu num prazo razoável; enfim, confiança nas transições entre diferentes estatutos de empregos.

A transposição da flexigurança para diferentes contextos depende, no entanto, da capacidade económica, da vontade política, dos sistemas de bem-estar social, do funcionamento das políticas activas do mercado de trabalho ou simplesmente dos interesses dos actores em presença. Ora, não se afigura que todas estas condições (ou pelo menos a maior parte delas) estejam reunidas no contexto português. Por exemplo, quanto aos actores do mercado de trabalho, parece pouco provável ver as organizações representativas de trabalhadores a negociarem com as organizações patronais condições de desemprego em vez de condições de emprego, predispondo-se a trocar postos de trabalho por horas de formação e meses de subsídio. Ainda assim, um possível sinal de confiança futura nos desígnios da flexigurança parece decorrer do acordo transnacional conjunto entre parceiros 
sociais europeus (Outubro 2007), pois apesar de não ter sido subscrito por todas as organizações nacionais (por exemplo, a CGTP não o subscreveu) veio estabelecer princípios de consenso entre os parceiros sociais europeus. Este pode ser um sinal mais benéfico do que contraproducente para os sistemas de relações laborais europeus.

\section{Referências bibliográficas}

A.A.V.V. (2007), Livro Branco das Relações Laborais. Lisboa: Ministério do Trabalho e da Solidariedade Social.

Araújo, Pedro (2008), A tirania do presente. Do trabalho para a vida às incertezas do desemprego. Coimbra: Quarteto.

Centeno, Mário; Novo, Álvaro (2008), "As políticas activas e passivas do mercado de trabalho”, Janus-Anuário de Relações Exteriores, 11, 154-155.

CGTP (2007), Livro Verde - modernizar o direito do trabalho para enfrentar os desafios do século XXI (resumo). Lisboa: CGTP.

Comissão das Comunidades Europeias (2006), Livro Verde. Modernizar o direito do trabalho para enfrentar os desafios do século XXI. Bruxelas: Comissão Europeia.

Commission of the European Communities (2007), Towards Common Principles of Flexicurity:

More and better jobs through flexibility and security. Brussels: Commission of the European Communities. Disponível em: http://eur-lex.europa.eu/LexUriServ/LexUriServ. do?uri=COM:2007:0359:FIN:EN:PDF.

Costa, Hermes Augusto; Araújo, Pedro (2009), As vozes do trabalho nas multinacionais: o impacto dos Conselhos de Empresa Europeus em Portugal. Coimbra: Almedina/CES, 223.

Dornelas, António et al. (2006), Livro verde sobre as relações laborais. Lisboa: Ministério do Trabalho e da Solidariedade Social.

Estanque, Elísio; Costa, Hermes Augusto (2007), "Flexigurança - do modelo dinamarquês à realidade portuguesa", Participação, Boletim sobre temas do trabalho, 18, 2-5.

ETUC (2007a), ETUC position on the European Commission's Green Paper "modernising and strengthening labour law to meet the challenges of the 21st century". Brussels: ETUC.

ETUC (2007b), The flexicurity debate and the challenges for the trade union movement. Brussels: ETUC.

ETUC/BUSINESSEUROPE/UEAPME/CEEP (2007), Key Challenges Facing European Labour Markets: A joint analysis of European social partners Disponível em: http:// www.ueapme.com/docs/pos_papers/2007/071018_cross_key_challenges.pdf.

Eurofound (2007), "Varieties of flexicurity: reflections on key elements of flexibility and security". Dublin: European Foundation for the Improvement of Living and Working Conditions 
Eurofound (2008), Flexicurity and industrial relations. Dublin: European Foundation for the Improvement of Living and Working Conditions

Eurostat/newsrelease (2009), Euroindicators 112/2009, 31.07.2009. Disponível em: http://epp.eurostat.ec.europa.eu/portal/page/portal/eurostat/home/.

Ferreira, António Casimiro (2007), "Flexigurança: a verdade da mentira”, Le Monde Diplomatique (ed. portuguesa), 6 de Dezembro, 2.

Ferreira, António Casimiro (2008a), "Trabalho digno e flexigurança”, Janus-Anuário de Relações Exteriores, 11, 200-201.

Ferreira, António Casimiro (2008b), “Trabalho digno e reforma dos direitos laborais”, Janus-Anuário de Relações Exteriores, 11, 202-203.

Ferreira, António Casimiro; Costa, Hermes Augusto (1998/99), "Para uma sociologia das relações laborais em Portugal”, Revista Crítica de Ciênciais Sociais, 52/53, 141-171.

Gallie, Duncan; Paugam, Serge (2000), "The social regulation of unemployment", in D. Gallie; S. Paugam (orgs.), Welfare regimes and the experience of unemployment in Europe. Oxford: Oxford University Press, 351-374.

Hespanha, Pedro; Møller, Iver Horneman (2001), "Activation policies and social inclusion in Denmark and Portugal”, Transfer-European Review of Labour and Research, 7 (1), 54-73.

Hespanha, Pedro; Portugal, Sílvia (2002), A transformação da família e a regressão da sociedade-providência. Porto: Comissão de Coordenação da Região Norte, 158.

Keune, Maarten; Jepsen, Maria (2007), "Not Balanced and Hardly New: The European Commission's quest for flexicurity”, Discussion \& Working Papers, WP 2007.01. Brussels: European Trade Union Institute for Research, Education and Health and Safety.

Kovács, Ilona (2005), "Emprego flexível em Portugal: alguns resultados de um projecto de investigação”, in I. Kovács (org.), Flexibilidade de emprego: riscos e oportunidades. Oeiras: Celta, 11-53.

Madsen, Per Kongshøj (2004), “The Danish model of 'flexicurity': experiences and lessons”, Transfer - European Review of Labour and Research, 10 (2), 187-207.

Muffels, Ruud; Luijkx, Ruud (2008), "Labour Market Mobility and Employment Security of Male Employees in Europe: 'Trade-off' or 'flexicurity'”?, Work, Employment and Society, 22 (2), 221-242.

Portugal, Sílvia (2006), Novas famílias, modos antigos. As redes sociais na produção de bem-estar (Tese de Doutoramento em Sociologia). Coimbra: Faculdade de Economia.

Santos, Boaventura de Sousa; Costa, Hermes Augusto (2004), "Introdução: para ampliar o cânone do internacionalismo operário", in B. S. Santos (org.), Trabalhar o mundo: os caminhos do novo internacionalismo operário. Porto: Afrontamento, 17-61.

Silva, José Almeida (2008), “Mercados transicionais ou flexigurança”, Janus-Anuário de Relações Exteriores, 11, 168-169.

Tangian, Andranik (2007), "European flexicurity: concepts, methodology and policies", Transfer-European Review of Labour and Research, 13 (4), 551-573. 
Transfer-European Review of Labour and Research (2004), thematic issue on flexicurity, $10(2)$.

UGT (2007), Parecer da UGT sobre o Livro Verde «modernizar o direito do trabalho para enfrentar os desafios do século XXI». Lisboa: UGT.

Valkenburg, Ben et al. (2001), "Work and inclusion", Transfer - European Review of Labour and Research, 7 (1), 12-24.

Wilthagen, Ton; Tros, Frank (2004), "The Concept of 'Flexicurity': A new approach to regulating employment and labour markets", Transfer-European Review of Labour and Research, 10 (2), 166-186. 